\title{
PReS-FINAL-2102: Comparison of sensitivity and specificity of MAS and HLH diagnostic guidelines in 362 children with MAS complicating systemic JIA
}

\author{
S Davi ${ }^{1 *}$, F Minoia ${ }^{1}$, AC Horne 2 , E Demirkaya ${ }^{3}$, N llowite ${ }^{4}$, A Insalaco ${ }^{5}$, M loseliani ${ }^{6}$, M Jelusic-Drazic ${ }^{7}$, MA Kapovic ${ }^{8}$, \\ O Kasapcopur ${ }^{9}$, I Kone-Paut ${ }^{10}$, L Lepore ${ }^{11}$, C Li ${ }^{12}$, S Magni-Manzoni ${ }^{5}$, D Maritsi $^{13}$, D Mccurdy $^{14}$, R Merino $^{15}$, \\ P Miettunen ${ }^{16}$, N Ruperto ${ }^{1}$, A Martini ${ }^{1}, \mathrm{RQ}$ Cron $^{17}$, A Ravelli ${ }^{1}$, \\ International Investigator Consortium for MAS Diagnostic Criteria
}

From 20th Pediatric Rheumatology European Society (PReS) Congress

Ljubljana, Slovenia. 25-29 September 2013

\section{Introduction}

Early diagnosis of macrophage activations syndrome (MAS) in systemic juvenile idiopathic arthritis (sjia) may be challenging because it may mimic the clinical features of the underlying disease or be confused with an infectious complication. However, the diagnostic value of the guidelines for hemophagocytic lymphohistiocytosis (HLH) or sjia-associated MAS has seldom been examined.

\section{Objectives}

To investigate the sensitivity and specificity of diagnostic guidelines for HLH and sjia-associated MAS in patients with sjia who developed MAS.

\section{Methods}

The study sample included 362 children with sjia who had MAS (diagnosed and treated as such by the attending physician) and 2 control groups with potentially "confusable" conditions, including active sjia without MAS ( $\mathrm{n}=404)$ and a systemic febrile infection requiring hospitalization $(n=345)$. Diagnostic guidelines for HLH and sjia-associated MAS were applied to all MAS and control patients. Because no patient had NK-cell activity and soluble CD25 determination available and bone marrow aspirate was performed in only a few patients, these 3 criteria were excluded from HLH guidelines. HLH criteria were, therefore, met when at least 4 of the 5 remaining variables were present. Sjia-associated MAS
Table 1

\begin{tabular}{lcccc}
\hline $\begin{array}{l}\text { Diagnostic } \\
\text { guidelines }\end{array}$ & \multicolumn{2}{c}{ MAS vs. Active sjia } & \multicolumn{2}{c}{$\begin{array}{c}\text { MAS vs. Systemic } \\
\text { infection }\end{array}$} \\
\cline { 2 - 5 } & Sensitivity & Specificity & Sensitivity & Specificity \\
\hline HLH & 0.19 & 1 & 0.19 & 1 \\
\hline Sjia-associated MAS & 0.79 & 0.92 & 0.79 & 0.8 \\
\hline
\end{tabular}

criteria were met when at least 2 laboratory criteria or at least 1 laboratory criterion and 1 clinical criterion were present. Sensitivity and specificity of guidelines in discriminating patients with MAS from control patients were assessed.

\section{Results}

The table shows the comparison of sensitivity and specificity of diagnostic guidelines.

\section{Conclusion}

The diagnostic guidelines for sjia-associated MAS revealed strong sensitivity and specificity, whereas HLH guidelines were highly specific, but lacked sensitivity. Sensitivity of HLH was mostly hampered by the excessive stringent threshold for cytopenia and hypofibrinogenemia, and the infrequent occurrence of splenomegaly in patients with MAS.

\section{Disclosure of interest}

None declared.

${ }^{1}$ Istituto Giannina Gaslini and University of Genova, Genova, Italy

Full list of author information is available at the end of the article 


\section{Authors' details}

'Istituto Giannina Gaslini and University of Genova, Genova, Italy.

2Department of Women's and Children's Health, Childhood Cancer Research Unit, Karolinska Institutet, Karolinska University Hospital Solna, Stockholm, Sweden. ${ }^{3}$ Gulhane Military Medical Faculty, Ankara, Turkey. ${ }^{4}$ Children's Hospital at Montefiore, Albert Einstein College of Medicine New Hyde Park, NY, United States. ${ }^{5}$ Ospedale Pediatrico Bambin Gesu', Rome, Italy. ${ }^{6} \mathrm{M}$. lashvili Children's Central Clinic, Tbilisi, Georgia. University Hospital Centre Zagreb, University School of Medicine, Croatia. ${ }^{8}$ Department for pulmology, allergology, clinical immunology and rheumatology, Zagreb, Croatia. ${ }^{9}$ Istanbul University, Cerrahpasa Medical Faculty, Istanbul, Turkey.

${ }^{10}$ Rhumatologie Pediatrique, Centre de reference national des maladies autoinflammatoires, Le kremlin Bicetre, Paris, France. ${ }^{11}$ Universita' degli Studi di Trieste, IRCCS Burlo Garofolo, Trieste, Italy. ${ }^{12}$ Beijing Children's Hospital, Capital, University of Medical Sciences, Beijing, China. ${ }^{13} 2$ nd Department of Academic Pediatrics, Athens Medical School, University of Athens, Athens, Greece. ${ }^{14}$ Department of Pediatrics, Children's Hospital of Orange County, CA, United States. ${ }^{15}$ Unidad De Reumatologia Pediatrica, Hospital Universitario La Paz, Madrid, Spain. ${ }^{16}$ Department of Pediatrics, Division of Pediatric Rheumatology, University of Calgary, Calgary, Canada. ${ }^{17}$ Children's Hospital of Alabama and University of Alabama at Birmingham, AL, United States.

Published: 5 December 2013

doi:10.1186/1546-0096-11-S2-P114

Cite this article as: Davi et al:: PReS-FINAL-2102: Comparison of sensitivity and specificity of MAS and HLH diagnostic guidelines in 362 children with MAS complicating systemic JIA. Pediatric Rheumatology 2013 11(Suppl 2):

P114.

\section{Submit your next manuscript to BioMed Central} and take full advantage of:

- Convenient online submission

- Thorough peer review

- No space constraints or color figure charges

- Immediate publication on acceptance

- Inclusion in PubMed, CAS, Scopus and Google Scholar

- Research which is freely available for redistribution

Submit your manuscript at www.biomedcentral.com/submit 